R. V. Voronov

\title{
THE FAULT-TOLERANT METRIC DIMENSION OF THE KING'S GRAPH
}

Petrozavodsk State University, 33, Lenina pr., Petrozavodsk, 185910, Russian Federation

The concept of resolving the set within a graph is related to the optimal placement problem of access points in an indoor positioning system. A vertex $w$ of the undirected connected graph $G$ resolves the vertices $u$ and $v$ of $G$ if the distance between vertices $w$ and $u$ differs from the distance between vertices $w$ and $v$. A subset $W$ of vertices of $G$ is called a resolving set, if every two distinct vertices of $G$ are resolved by some vertex of $w \in W$. The metric dimension of $G$ is a minimum cardinality of its resolving set. The set of access points of the indoor positioning system corresponds to the resolving set of vertices in the graph. The minimum number of access points required to locate each of the vertices corresponds to the metric dimension of graph. A resolving set $W$ of the graph $G$ is fault-tolerant if $W \operatorname{minus}\{w\}$ is also a resolving set of $G$, for each $w \in W$. The fault-tolerant metric dimension of the graph $G$ is a minimum cardinality of the fault-tolerant resolving set. In the indoor positioning system the fault-tolerant resolving set provides correct information even when one of the access points is not working. The article describes a special case of a graph called the king's graph, or the strong product of two paths. The king's graph is a building model in some indoor positioning systems. In this article we give an upper bound for the fault-tolerant metric of the king's graph and a formula for a particular case of the king's graph. Refs 20. Figs 2.

Keywords: fault-tolerant metric dimension, strong product graphs, king's graph, access points of indoor positioning system.

\section{Р. В. Воронов}

\section{ОТКАЗОУСТОЙЧИВАЯ МЕТРИЧЕСКАЯ РАЗМЕРНОСТЬ ГРАФА ХОДОВ ШАХМАТНОГО КОРОЛЯ}

Петрозаводский государственный университет, Российская Федерация, 185910, Петрозаводск, пр. Ленина, 33

В некотором приближении аналогом задачи оптимального размещения точек доступа системы внутреннего позиционирования служит задача определения метрической размерности графа и построения его разрешающего множества. Пусть вершина $w$ неориентированного связного графа $G$ различает вершины $u$ и $v$ графа $G$, если расстояние между вершинами $w$ и $u$ отличается от расстояния между вершинами $w$ и $v$. Подмножество $W$ вершин графа $G$ называется разрешающим, если для каждой пары вершин $u$ и $v$ графа $G$ найдется различающая их вершина $w \in W$. Метрическая размерность графа - это минимальное число вершин в разрешающем подмножестве. Точкам доступа системы внутреннего позиционирования соответствует разрешающее множество вершин графа, а минимально необходимому числу точек доступа - метрическая размерность графа. Разрешающее множество называется отказоустойчивым, если оно остается разрешающим, даже если из него удалить любую его вершину. Отказоустойчивая метрическая размерность графа - это минимальное число вершин в отказоустойчивом разрешающем подмножестве, что в системе внутреннего позиционирования соответствует возможности определения местоположения объекта даже в случае потери информации от одной из точек доступа. Рассмотрен один частный случай графа - сильное произведение двух простых цепей, называемое иначе графом ходов шахматного короля. Установлена верхняя граница для отказоустойчивой

Voronov Roman Vladimirovich - PhD of technical sciences, associate professor; rvoronov76@gmail.com

Воронов Роман Владимирович - кандидат технических наук, доцент; rvoronov76@gmail.com

(C) Санкт-Петербургский государственный университет, 2017 
метрической размерности графа ходов короля и приведена формула для одного частного случая. Библиогр. 20 назв. Ил. 2.

Ключевые слова: отказоустойчивая метрическая размерность, сильное произведение графов, граф ходов короля, точки доступа системы внутреннего позиционирования.

Introduction. The concepts of the graph theory is used to describe the problem of navigation in the network [1] and in indoor positioning system to model the floorplan of the building. The building floorplan is modeled by the undirected connected graph $G=(V, E)$, where the vertices of the set $V$ represent small zones, and the edges of the set $E$ denote the possibility of moving directly between zones. A zone may consist of only one room, and big rooms may be partitioned into several zones. The distance $d(u, v)$ between vertices $u$ and $v$ is the minimum number of edges in the path having these two vertices as its endpoints.

In some vertices of the graph we can place the landmarks of the navigation system or access points of the indoor positioning system [2]. The set of access points of the indoor positioning system corresponds to the resolving set of vertices in graph. The minimum number of access points required to locate each of the vertices is called the metric dimension.

Formally, let $W=\left\{w_{1}, \ldots, w_{k}\right\}$ be an ordered subset of vertices of graph $G$. The ordered $k$-tuple $r(v \mid W)=\left(d\left(v, w_{1}\right), \ldots, d\left(v, w_{k}\right)\right)$ is called a representation of the vertex $v$ with respect to $W$. The subset of vertices $W \subset V$ is called a resolving set, if every two vertices $u, v$ have distinct representations $r(u \mid W)$ and $r(v \mid W)$. The metric dimension $\beta(G)$ of the graph $G$ is a minimum cardinality of the resolving set for $G$. A resolving set with the minimum number of vertices is called a metric basis for $G$.

In other words, the metric dimension of the graph $G$ is the smallest integer $m$, for which subset $W \subset V$ exists, such that $|W|=m$ and for every pair of vertices $u, v \in V$ there is $w \in W$, that the distance between the vertices $w$ and $u$ is not equal to the distance between the vertices $w$ and $v$. We also will say, that a vertex $w$ of the graph $G$ resolves the vertices $v_{1}$ and $v_{2}$ in $G$ (is able to distinguish $v_{1}$ and $\left.v_{2}\right)$, if $d\left(w, v_{1}\right) \neq d\left(w, v_{2}\right)$.

A resolving set $W$ of the graph $G$ is fault-tolerant if $W \backslash\{w\}$ is also a resolving set of $G$, for each $w \in W$. The fault-tolerant metric dimension $\beta^{\prime}(G)$ of $G$ is a minimum cardinality of the fault-tolerant resolving set. A fault-tolerant resolving set of cardinality $\beta^{\prime}(G)$ is called a fault-tolerant metric basis of $\mathrm{G}$.

The strong product $G_{1} \otimes G_{2}$ of the graphs $G_{1}=\left(V_{1}, E_{1}\right)$ and $G_{2}=\left(V_{2}, E_{2}\right)$ is the graph $G=(V, E)$, such that $V=V_{1} \times V_{2}$ and two distinct vertices $\left(u_{1}, u_{2}\right)$ and $\left(v_{1}, v_{2}\right)$ are adjacent in $G$ if and only if

$u_{1}=v_{1}$ and $\left(u_{2}, v_{2}\right) \in E_{2}$, or

$u_{2}=v_{2}$ and $\left(u_{1}, v_{1}\right) \in E_{1}$, or

$\left(u_{1}, v_{1}\right) \in E_{1}$ and $\left(u_{2}, v_{2}\right) \in E_{2}$.

Now we denote $P_{m}=\left(I_{m}, J_{m}\right)$ - path graph, where $m$ is natural number, $I_{m}=$ $\{1, \ldots, m\}$ and $J_{m}=\{(i, i+1) \mid i=1, \ldots, m-1\}$.

The king's graph with natural parameters $(m, n)$ is a graph $P_{m} \otimes P_{n}$, that represents all legal moves of the king chess piece on a $m \times n$ chessboard. The vertex set of the $m \times n$ king's graph is the Cartesian product $V=I_{m} \times I_{n}$. It is easy to check, that $d\left(v_{1}, v_{2}\right)=\max \left\{\left|i_{1}-i_{2}\right|,\left|j_{1}-j_{2}\right|\right\}$ for any two vertices $v_{1}=\left(i_{1}, j_{1}\right)$ and $v_{2}=\left(i_{2}, j_{2}\right)$ of graph $P_{m} \otimes P_{n}$.

It is known that $\beta\left(P_{n} \otimes P_{n}\right)=3[3], \beta^{\prime}\left(P_{n} \otimes P_{n}\right)=4$ [4] for $n \geqslant 2$. The following theorem is proved in [5]. 
Theorem 1 [5]. For any integers $n$ and $m$ such that $2 \leqslant m<n$,

$$
\beta\left(P_{m} \otimes P_{n}\right)=\left\lceil\frac{n+m-2}{m-1}\right\rceil .
$$

Figure 1 shows graph $P_{3} \otimes P_{12}$. Vertices of metric basis are black, $\beta\left(P_{3} \otimes P_{12}\right)=7$.

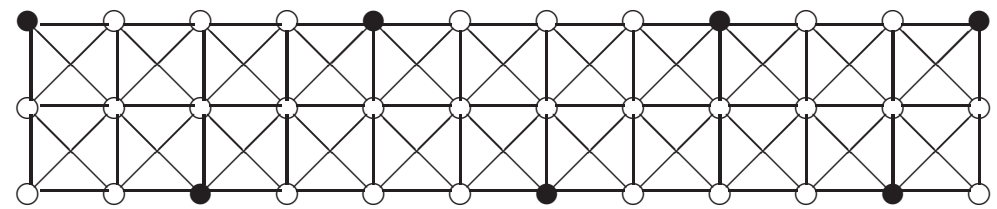

Fig. 1. Metric basis for graph $P_{3} \otimes P_{12}$

In this paper we study the problem of finding a sharp bound for the fault-tolerant metric dimension of the king's graph and the exact value for a particular case. We assume that $n>m$ for the graph $P_{m} \otimes P_{n}$. The case $m>n$ is considered analogously.

Related works. The problems of finding the metric dimension of a graph were introduced independently by Slater (1975) and Harary and Melter (1976) [6, 7]. Melter studied the metric dimension problem for the tree. Garey and Johnson (1979) noted that determining the metric dimension of the graph is an NP-complete problem. Khuller, Raghavachari, Rosenfeld (1996) described the application of the metric dimension problem in the field of computer science and robotics and outlined the graphs with metric dimension 1 and 2 [8]. Chartrand, Eroh, Johnson, Oellermann (2000) described the application in chemistry [9]. The strong metric dimension problem was introduced by Sebö and Tannier (2004) [10]. Fehr, Gosselin, Oellermann (2006) studied the metric dimension for different types of graphs, for exsample Cayley digraphs [11]. The concept of the fault-tolerant metric dimension was introduced by Hernando, Mora, Slater, Wood (2008) [12]. Okamoto, Phinezy, Zhang (2010) introduced the concept of local metric dimension [13]. The metric dimension of the random graph was considered by Bollobas, Mitsche, Pralat (2012) [14]. The formulas for metric dimension of many graph classes were studied [15-17]. Zejnilović, Mitsche, Gomes and Sinopoli (2016) extended the metric dimension to the graphs with missing edges [18].

The main results. We present the main result in the form of two theorems.

The first theorem gives the upper bounds for the fault-tolerant metric dimension of the king's graph.

Theorem 2. For any integers $n$ and $m$, such that $2 \leqslant m<n$, the following assertion hold. If $(m-1)$ is a divisor of $(n-2)$, then

$$
\beta^{\prime}\left(P_{m} \otimes P_{n}\right) \leqslant 2 \frac{n-2}{m-1}+3,
$$

otherwise

$$
\beta^{\prime}\left(P_{m} \otimes P_{n}\right) \leqslant 2\left\lceil\frac{n-1}{m-1}\right\rceil+2 .
$$

There is a formula for the fault-tolerant metric dimension for a partcular case of king's graph in second theorem.

Theorem 3. For any integers $n$ and $m$, such that $m$ is even, $m \geqslant 2, n \geqslant 2 m-1$ and $(m-1)$ is a divisor of $(n-1)$,

$$
\beta^{\prime}\left(P_{m} \otimes P_{n}\right)=2 \frac{n-1}{m-1}+2 .
$$


First we introduce some definitions and prove some lemmas.

For the integers $m, n, j$, such that $2 \leqslant m<n$ and $j \in\{1, \ldots, n\}, V_{j}$ denotes the vertex subset of graph $P_{m} \otimes P_{n}$, where $V_{j}=\{(i, j) \mid i=1, \ldots, m\}$. We introduce the notation

$$
V_{j_{1}, j_{2}}=\bigcup_{j=j_{1}}^{j_{2}} V_{j}
$$

Lemma 1. Let $2 \leqslant m<n$ be integers. Let $W$ be a resolving set of graph $G=P_{m} \otimes P_{n}$. If $v_{1}=\left(i_{1}, j^{\prime}\right), v_{2}=\left(i_{2}, j^{\prime}\right)$ are vertices of $G$ and $w=(i, j) \in W$, such that $\left|j-j^{\prime}\right| \geqslant$ $m-1$, then vertex $w$ does not resolve the vertices $v_{1}$ and $v_{2}$.

Pro of. Since $\left|i-i^{\prime}\right| \leqslant m-1$ for all $i^{\prime}=1, \ldots, m$, then

$$
d\left(w, v_{1}\right)=d\left(w, v_{2}\right)=\left|j-j^{\prime}\right| .
$$

Hence, then vertex $w$ does not resolve the vertices $v_{1}$ and $v_{2}$. Lemma is proved.

Lemma 2. Let $2 \leqslant m<n$ be integers. Let $W$ be a resolving set of graph $P_{m} \otimes P_{n}$. Then for any $j^{\prime} \in\{1, \ldots, n\}$ there exists vertex $w=(i, j) \in W$, such that $\left|j-j^{\prime}\right|<m-1$.

Pro of. Suppose, for the contrary, that exists $j^{\prime} \in\{1, \ldots, n\}$, such that for all $w=$ $(i, j) \in W$ we have $\left|j-j^{\prime}\right| \geqslant m-1$. We now take any distinct $i_{1}, i_{2} \in\{1, \ldots, m\}$. According to the Lemma 1, no vertex $w \in W$ resolve the vertices $v_{1}=\left(i_{1}, j^{\prime}\right)$ and $v_{2}=\left(i_{2}, j^{\prime}\right)$. This contradiction proves the lemma.

Lemma 3. Let $2 \leqslant m<n$ be integers and let $W$ be a resolving set of graph $P_{m} \otimes P_{n}$. Let $j^{\prime} \in\{1, \ldots, n\}$. If there exists only one vertex $w=(i, j) \in W$, such that $\left|j-j^{\prime}\right|<m-1$, then $j=j^{\prime}$.

Pro of. Suppose, for the contrary, that exists $j^{\prime} \in\{1, \ldots, n\}$, that there exists only one vertex $w=(i, j) \in W$, such that $\left|j-j^{\prime}\right|<m-1$, but $j \neq j^{\prime}$.

Let $i_{1}=i$. If $i<m$, then let $i_{2}=i+1$. If $i=m$, then let $i_{2}=i-1$. Let $v_{1}=\left(i_{1}, j^{\prime}\right)$, $v_{2}=\left(i_{2}, j^{\prime}\right)$. Then $d\left(w, v_{1}\right)=\left|j-j^{\prime}\right|, d\left(w, v_{2}\right)=\left|j-j^{\prime}\right|$, hence $d\left(w, v_{1}\right)=d\left(w, v_{2}\right)$ and vertex $w \in W$ does not resolve the vertices $v_{1}$ and $v_{2}$. In addition, according to the Lemma 1, no vertex in $W \backslash\{w\}$ that distinguish vertices $v_{1}$ and $v_{2}$.

This contradiction proves the lemma.

Lemmas 2 and 3 lead to the next results.

Corollary 1. Let $2 \leqslant m<n$ be integers and let $W$ be a resolving set of graph $P_{m} \otimes P_{n}$. Then for all $j \in\{1, \ldots, n\}$ there exists $w \in W$, such that $w \in V_{j}$ or exist two distinct vertices $\left(i_{1}, j_{1}\right) \in W$ and $\left(i_{2}, j_{2}\right) \in W$, that $\left|j-j_{1}\right|<m-1$ and $\left|j-j_{2}\right|<m-1$.

Corollary 2. Let $2 \leqslant m<n$ be integers and let $W$ be a fault-tolerant resolving set of graph $P_{m} \otimes P_{n}$. Then for all $j \in\{1, \ldots, n\}$ there exist two distinct vertices $w_{1}, w_{2} \in W$, such that $w_{1}, w_{2} \in V_{j}$ or exist three distinct vertices $\left(i_{1}, j_{1}\right) \in W,\left(i_{2}, j_{2}\right) \in W$ and $\left(i_{3}, j_{3}\right) \in W$, that $\left|j-j_{1}\right|<m-1,\left|j-j_{2}\right|<m-1$ and $\left|j-j_{3}\right|<m-1$.

Lemma 4 [19]. A resolving set $W$ of a graph $G$ is fault-tolerant if and only if every pair of vertices in $G$ is resolved by at least two elements of $W$.

Lemma 5. Let $G=P_{m} \otimes P_{n}$, where $m$ is even, $n \geqslant m \geqslant 2$. Let $W$ be a fault-tolerant resolving set of $G$. Then for all $j \in\{0, \ldots, n-m+1\}$,

$$
\left|V_{j+1, j+m-1} \bigcap W\right| \geqslant 2 \text {. }
$$

Proof. Let $j \in\{0, \ldots, n-m+1\}, V^{\prime}=V_{j+1, j+m-1}, v_{1}=\left(\frac{m}{2}, j+\frac{m}{2}\right), v_{2}=$ $\left(\frac{m}{2}+1, j+\frac{m}{2}\right)$. In this case $v_{1}, v_{2} \in V^{\prime}$. Let $V$ be the vertex set of graph $G$. 
By Lemma 4 for the vertices $v_{1}, v_{2}$ there exist $w_{1}, w_{2} \in W, w_{1} \neq w_{2}$, such that $d\left(w_{1}, v_{1}\right) \neq d\left(w_{1}, v_{2}\right)$ and $d\left(w_{2}, v_{1}\right) \neq d\left(w_{2}, v_{2}\right)$.

Consider a vertex $w=(i, k) \in V \backslash V^{\prime}$. Since $\left|i-\frac{m}{2}\right| \leqslant \frac{m}{2},\left|i-\frac{m}{2}-1\right| \leqslant \frac{m}{2}$ and $\left|k-j-\frac{m}{2}\right| \geqslant \frac{m}{2}$ we have $d\left(w, v_{1}\right)=\left|k-j-\frac{m}{2}\right|$ and $d\left(w, v_{2}\right)=\left|k-j-\frac{m}{2}\right|$. Hence $d\left(w, v_{1}\right)=d\left(w, v_{2}\right)$ and no vertex in $V \backslash V^{\prime}$ is able to distinguish $v_{1}$ and $v_{2}$.

Thus $w_{1}, w_{2} \in V^{\prime} \cap W$. Therefore, the proof is complete.

Lemma 6. Let $G=P_{m} \otimes P_{n}$, where $m \geqslant 2$ and $n \geqslant 2$. Let $W$ be a fault-tolerant resolving set of $G$ and let $j \in\{1, \ldots, n\}$. If exist distinct vertices $w_{1}, w_{2} \in W$, that $W=\left\{w_{1}, w_{2}\right\}$ or $d\left(w, v_{1}\right)=d\left(w, v_{2}\right)$ for any $w \in W \backslash\left\{w_{1}, w_{2}\right\}$ and for each pair of distinct vertices $v_{1}, v_{2} \in V_{j}$, then $w_{1}, w_{2} \in V_{j}$.

Proof. Let $G, j, w_{1}$ and $w_{2}$ be as in the hypotheses. Let $V$ be the vertex set of graph $G$. By Lemma 4 for every pair of vertices $v_{1}, v_{2} \in V_{j}$ there are at least two vertices of $W$, which are able to distinguish $v_{1}$ and $v_{2}$. Hence, we have that $d\left(w_{1}, v_{1}\right) \neq d\left(w_{1}, v_{2}\right)$ and $d\left(w_{2}, v_{1}\right) \neq d\left(w_{2}, v_{2}\right)$ for all different $v_{1}, v_{2} \in V$.

We will show that $w_{1} \in V_{j}$. Suppose, for the contrary, that $w_{1}=\left(i, j_{1}\right)$ and $j_{1} \neq j$. If $i=1$, then $w_{1}$ is not able to distinguish $v_{1}=(1, j) \in V_{j}$ and $v_{2}=(2, j) \in V_{j}$. If $i>1$, then $w_{1}$ is not able to distinguish $v_{1}=(i, j) \in V_{j}$ and $v_{2}=(i-1, j) \in V_{j}$. In both cases we have $d\left(w_{1}, v_{1}\right)=d\left(w_{1}, v_{2}\right)=\left|j_{1}-j\right|$ and we get a contradiction.

The proof that $w_{2} \in V_{j}$ is deduced analogously.

Lemma is proved.

Lemma 7. Let $G=P_{m} \otimes P_{n}$, where $m \geqslant 2$ and $n \geqslant 2 m-3$. Let $W$ be a fault-tolerant resolving set of $G$ and let $\tilde{V}_{j}=V_{\max \{1, j-m+2\}, \min \{n, j+m-2\}}$, where $j \in\{1, \ldots, n\}$. If

$$
\left|\tilde{V}_{j} \bigcap W\right|=2
$$

then $\tilde{V}_{j} \cap W \subset V_{j}$.

Proof. Let $j \in\{1, \ldots, n\}$ and let $\left\{w_{1}, w_{2}\right\}=\tilde{V}_{j} \cap W$. Let $V$ be the vertex set of graph $G$. We differentiate two cases for $V \backslash \tilde{V}_{j}$.

Case 1: $V \backslash \tilde{V}_{j} \neq \emptyset$. Consider a vertex $w=(i, k) \in V \backslash \tilde{V}_{j}$ and any different vertices $v_{1}=\left(i_{1}, j\right) \in V_{j}, v_{2}=\left(i_{2}, j\right) \in V_{j}$. Since $\left|i-i_{1}\right| \leqslant m-1,\left|i-i_{2}\right| \leqslant m-1$ and $|k-j| \geqslant m-1$ we have $d\left(w, v_{1}\right)=|k-j|$ and $d\left(w, v_{2}\right)=|k-j|$. Hence $d\left(w, v_{1}\right)=d\left(w, v_{2}\right)$ and no vertex in $V \backslash \tilde{V}_{j}$ is able to distinguish $v_{1}$ and $v_{2}$. Thus no vertex in $W \backslash\left\{w_{1}, w_{2}\right\}$ is able to distinguish any two different vertices $u, v \in V_{j}$. Therefore, by Lemma $6 w_{1}, w_{2} \in V_{j}$.

Case 2: $V \backslash \tilde{V}_{j}=\emptyset$. In this case we have $W=\left\{w_{1}, w_{2}\right\}$, by Lemma $6 w_{1}, w_{2} \in V_{j}$ and we conclude the proof.

Lemma 8. Let $G=P_{m} \otimes P_{n}$, where $m \geqslant 2$ and $n \geqslant m$. Let $W$ be a fault-tolerant resolving set of $G$. Then

$$
\left|V_{n-m+1, n} \bigcap W\right| \geqslant 3 .
$$

Proof. By Corollary 2 we have $\left|V_{n} \bigcap W\right| \geqslant 2$ or $\left|V_{n-m+2, n} \bigcap W\right| \geqslant 3$ and, additionally, $\left|V_{n-1} \bigcap W\right| \geqslant 2$ or $\left|V_{n-m+1, n} \bigcap W\right| \geqslant 3$. Anyway we get $\left|V_{n-m+1, n} \bigcap W\right| \geqslant 3$. The lemma is proved.

Now we present the proof of the Theorem 2.

Proof. Let $2 \leqslant m<n$ be integers and let $G=P_{m} \otimes P_{n}$. In paper [20] is shown, how construct a resolving set $W$ (a metric generator) for graph $G$, such that

$$
|W|=k=\left\lceil\frac{n-1}{m-1}\right\rceil+1 .
$$

We use that construction and consider two cases. 
Case 1: $(m-1)$ is a divisor of $(n-2)$. Let

$$
\begin{aligned}
& w_{1 t}= \begin{cases}(1, \min \{n,(t-1)(m-1)+1\}), & \text { if } t \text { is odd }, \\
(m, \min \{n,(t-1)(m-1)+1\}), & \text { otherwise, }\end{cases} \\
& t=1, \ldots, k, \\
& w_{2 t}= \begin{cases}(m, \min \{n,(t-1)(m-1)+1\}), & \text { if } t \text { is odd }, \\
(1, \min \{n,(t-1)(m-1)+1\}), & \text { otherwise, }\end{cases} \\
& t=1, \ldots, k-1 \text {, } \\
& w_{2 k}= \begin{cases}(1, n), & \text { if } k \text { is odd } \\
(m, n), & \text { otherwise }\end{cases} \\
& w_{3 t}= \begin{cases}(1, \min \{n,(t-1)(m-1)+1\}), & \text { if } t \text { is odd }, \\
(m, \min \{n,(t-1)(m-1)+1\}), & \text { otherwise, }\end{cases} \\
& t=1, \ldots, k-1, \\
& w_{3 k}= \begin{cases}(1, n-1), & \text { if } k \text { is odd }, \\
(m, n-1), & \text { otherwise. }\end{cases}
\end{aligned}
$$

For $i=1, \ldots, 3$ let

$$
W_{i}=\left\{w_{i t} \mid t=1, \ldots, k\right\} .
$$

$W_{1}$ is resolving sets of $G[20]$. Analogously we can show that $W_{2}, W_{3}$ are resolving sets of $G$.

Let $U=\left\{w_{1 k-1}, w_{1 k}, w_{3 k}\right\}$. It is obviously, that $w_{1 k-1}=w_{3 k-1}, w_{1 k}=w_{2 k}, w_{3 k}=$ $w_{2 k-1}, W_{1} \backslash U=W_{3} \backslash U,\left(W_{1} \backslash U\right) \cap\left(W_{2} \backslash U\right)=\emptyset$. Let $W=W_{1} \cup W_{2} \bigcup W_{3}$. We differentiate five cases. If $w \in W_{1} \backslash U$, then $W_{2} \subset W \backslash\{w\}$. If $w \in W_{2} \backslash U$, then $W_{1} \subset W \backslash\{w\}$. If $w=w_{1 k-1}$, then $W_{2} \subset W \backslash\{w\}$. If $w=w_{1 k}$, then $W_{3} \subset W \backslash\{w\}$. If $w=w_{3 k}$, then $W_{1} \subset W \backslash\{w\}$. We can point out that, in any case, $W \backslash\{w\}$ is resolving sets of $G$. Thus $W$ is a fault-tolerant resolving set.

Case 2: $(m-1)$ is not a divisor of $(n-2)$. Let

$$
\begin{gathered}
w_{1 t}= \begin{cases}(1, \min \{n,(t-1)(m-1)+1\}), & \text { if } t \text { is odd } \\
(m, \min \{n,(t-1)(m-1)+1\}), & \text { otherwise, }\end{cases} \\
w_{2 t}= \begin{cases}(m, \min \{n,(t-1)(m-1)+1\}), & \text { if } t \text { is odd }, \\
(1, \min \{n,(t-1)(m-1)+1\}), & \text { otherwise, }\end{cases} \\
t=1, \ldots, k .
\end{gathered}
$$

For $i=1,2$ let

$$
W_{i}=\left\{w_{i t} \mid t=1, \ldots, k\right\} .
$$

$W_{1}, W_{2}$ are resolving sets of $G[20]$.

It is obviously, that $W_{1} \cap W_{2}=\emptyset$. Let $W=W_{1} \cup W_{2}$. We differentiate two cases for $w \in W$. If $w \in W_{1}$, then $W_{2} \subset W \backslash\{w\}$, if $w \in W_{2}$, then $W_{1} \subset W \backslash\{w\}$. We can point out that, in any case, $W \backslash\{w\}$ is resolving sets of $G$. Thus $W$ is a fault-tolerant resolving set.

This proves the theorem.

Now we present the proof of the Theorem 3 .

P r o of. Let $n$ and $m$ be integers, such that $m$ is even, $m \geqslant 2, n \geqslant 2 m-1$ and $(m-1)$ is a divisor of $(n-1)$. Let $W$ be a fault-tolerant metric basis of $P_{m} \otimes P_{n}$, and let $V$ be the vertex set of $P_{m} \otimes P_{n}$. 
We denote $k=\frac{n-m}{m-1}$. By Lemma 5 we have for all $t \in\{0, \ldots, k-1\}$

$$
\left|V_{t(m-1)+1,(t+1)(m-1)} \bigcap W\right| \geqslant 2 .
$$

By Lemma 8 we have

$$
\left|V_{n-m+1, n} \bigcap W\right| \geqslant 3
$$

We consider two cases.

Case 1. If there exists $t \in\{0, \ldots, k-1\}$ such that

$$
\left|V_{t(m-1)+1,(t+1)(m-1)} \bigcap W\right| \geqslant 3
$$

since $V$ is the union of sets, that are disjoint,

$$
V=\bigcup_{t=0}^{k-1} V_{t(m-1)+1,(t+1)(m-1)} \bigcup V_{n-m+1, n},
$$

then

$$
|W| \geqslant 2(k-1)+3+3=2 k+4 .
$$

Case 2. We assume, that for all $t \in\{0, \ldots, k-1\}$,

$$
\left|V_{t(m-1)+1,(t+1)(m-1)} \bigcap W\right|=2 .
$$

We first consider that $t=0$ :

$$
\left|V_{1, m-1} \bigcap W\right|=2 .
$$

Then Lemma 7 leads to $V_{1, m-1} \bigcap W \subset V_{1}$, in particular

$$
\left|V_{1} \bigcap W\right|=2 \text {. }
$$

We now take $t=1$ in (1) and we get

$$
\left|V_{m, 2(m-1)} \bigcap W\right|=2 .
$$

Since $V_{2, m-1} \bigcap W=\emptyset$ we can notice, that

$$
\left|V_{2,2(m-1)} \bigcap W\right|=2 \text {. }
$$

Then Lemma 7 leads to $V_{2,2(m-1)} \cap W \subset V_{m}$, in particular

$$
\left|V_{2, m} \bigcap W\right|=2 .
$$

Further it is analogically proved by mathematical induction, that

$$
\left|V_{t(m-1)+2,(t+1)(m-1)+1} \bigcap W\right|=2
$$

for all $t=1, \ldots, k-2$. 
By Lemma 5 we have

$$
\left|V_{(k-1)(m-1)+2, k(m-1)+1} \bigcap W\right| \geqslant 2
$$

and

$$
\left|V_{k(m-1)+2, n} \bigcap W\right| \geqslant 2 .
$$

Since $V$ is the union of sets, that are disjoint,

$$
V=\bigcup_{t=0}^{k} V_{t(m-1)+2,(t+1)(m-1)+1} \bigcup V_{1},
$$

and taking into account the above (2)-(6), we deduce

$$
|W| \geqslant 2 k+4 \text {. }
$$

According to the two cases above we have

$$
\beta^{\prime}\left(P_{m} \otimes P_{n}\right)=|W| \geqslant 2 k+4=2 \frac{n-1}{m-1}+2 .
$$

By Theorem 2 we have $\beta^{\prime}\left(P_{m} \otimes P_{n}\right) \leqslant 2 \frac{n-1}{m-1}+2$. Hence

$$
\beta^{\prime}\left(P_{m} \otimes P_{n}\right)=2 \frac{n-1}{m-1}+2 .
$$

This proves the theorem.

Figure 2 shows graph $P_{3} \otimes P_{11}$. Vertices of the fault-tolerant metric basis are black, $\beta^{\prime}\left(P_{3} \otimes P_{11}\right)=12$.

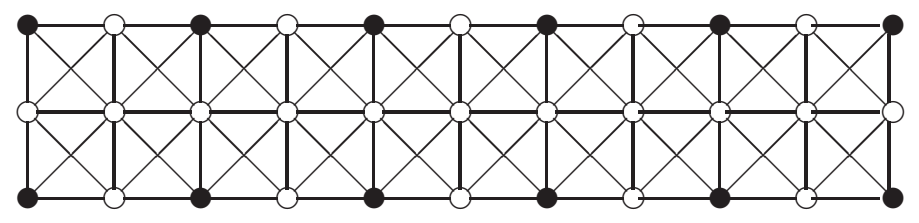

Fig 2. The fault-tolerant metric basis for graph $P_{3} \otimes P_{11}$

Conclusion. Theorem 3 leads to the following inference. The fault-tolerant metric basis for a partcular case of the king's graph contains two times more vertices than the metric basis does. Our conjecture consists of the statement that the upper bound for the fault-tolerant metric dimension of the king's graph from Theorem 2 is an exact value.

\section{References}

1. Krilatov A. Yu. Optimal'nye strategii upravlenija transportnymi potokami na seti iz parallel'nyh kanalov [Optimal strategies for traffic flow management on the transportation network of parallel links]. Vestnik of Saint Petersburg University. Series 10. Applied Mathematics. Computer Science. Control Processes, 2014, iss. 2, pp. 120-129. (In Russian)

2. Raj F. S., George A. On the metric dimension of few network sheets. Robotics, Automation, Control and Embedded Systems - RACE, Intern. conference on robotics. IEEE, 2015, pp. 1-6.

3. Melter R. A., Tomescu I. Metric bases in digital geometry. Computer Vision, Graphics, and Image Processing, 1984, vol. 25, no. 1, pp. 113-121. 
4. Chaudhry M. A., Javaid I., Salman M. Fault-tolerant metric and partition dimension of graphs. Utilitas Mathematica, 2010, vol. 83, pp. 187-199.

5. Barragán-Ramírez G. A., Rodríguez-Velázquez J. A. The local metric dimension of strong product graphs. Graphs and Combinatorics, 2016, vol. 32, no. 4, pp. 1263-1278.

6. Harary F., Melter R. A. On the metric dimension of a graph. Ars Combinatoria, 1976, vol. 2, pp. 191-195.

7. Slater P. J. Leaves of trees. Proc. 6th Southeastern Conference on Combinatorics, Graph Theory and Computing, 1975, pp. 549-559.

8. Khuller S., Raghavachari B., Rosenfeld A. Landmarks in graphs. Discrete Applied Mathematics, 1996, vol. 70, no. 3, pp. 217-229.

9. Chartrand G., Eroh L., Johnson M. A., Oellermann O. R. Resolvability in graphs and the metric dimension of a graph. Discrete Applied Mathematics, 2000, vol. 105, pp. 99-113.

10. Sebö A., Tannier E. On metric generators of graphs. Mathematics of Operations Research, 2004, vol. 29, no. 2, pp. 383-393.

11. Fehr M., Gosselin S., Oellermann O. The metric dimension of Cayley digraphs. Discrete Mathematics, 2006, vol. 306, pp. 31-41.

12. Hernando C., Mora M., Slater P. J., Wood D. R. Fault-tolerant metric dimension of graphs. Proc. Intern. conference Convexity in Discrete Structures, Ramanujan Mathematical Society Lecture Notes, 2008, no. 5, pp. 81-85.

13. Okamoto F., Phinezy B., Zhang P. The local metric dimension of a graph. Mathematica Bohemica, 2010, vol. 135, no. 3, pp. 239-255.

14. Bollobas B., Mitsche D., Pralat P. Metric dimension for random graphs. arXiv preprint arXiv:1208.3801, 2012 (Available at: https://arxiv.org/pdf/1208.3801.pdf. (accessed: 1.12.2016).)

15. Epstein L., Levin A., Woeginger G. J. The (weighted) metric dimension of graphs: hard and easy cases. Algorithmica, 2015, vol. 72, no. 4, pp. 1130-1171.

16. Imran M. On dimensions of some infinite regular graphs generated by infinite hexagonal grid. Utilitas Mathematica, 2013, vol. 92, pp. 3-15.

17. Klein D. J., Yi E. A comparison on metric dimension of graphs, line graphs, and line graphs of the subdivision graphs. European Journal of Pure and Applied Mathematics, 2012, vol. 5, no. 3, pp. 302-316.

18. Zejnilović S., Mitsche D., Gomes J., Sinopoli B. Extending the metric dimension to graphs with missing edges. Theoretical Computer Science, 2016, vol. 609, pp. 384-394.

19. Javaid I., Salman M., Chaudhry M. A., Shokat S. Fault-tolerance in resolvability. Utilitas Mathematica, 2009, vol. 80, pp. 263-275.

20. Rodríguez-Velázquez J. A., Kuziak D., Yero I. G., Sigarreta J. M. The metric dimension of strong product graphs. Carpathian Journal of Mathematics, 2015, vol. 31, no. 2, pp. 261-268.

For citation: Voronov R. V. The fault-tolerant metric dimension of the king's graph. Vestnik of Saint Petersburg University. Applied Mathematics. Computer Science. Control Processes, 2017, vol. 13, iss. 3, pp. 241-249. DOI: 10.21638/11701/spbu10.2017.302

Статья рекомендована к печати проф. А. П. Жабко.

Статья поступила в редакцию 11 декабря 2016 г.

Статья принята к печати 8 июня 2017 г.

Вестник СПбГУ. Прикладная математика. Информатика... 2017. Т. 13. Вып. 3 